CORRECTION

\title{
Correction: Pigment epithelium-derived factor promotes tumor metastasis through an interaction with laminin receptor in hepatocellular carcinomas
}

Jianjing Hou, Chao Ge, Meiling Cui, Tengfei Liu, Xiaoqin Liu, Hua Tian, Fangyu Zhao, Taoyang Chen, Ying Cui, Ming Yao, Jinjun Li and Hong Li

(c) The Author(s) 2021

Cell Death and Disease (2021)12:718; https://doi.org/10.1038/s41419-021-03975-3

Correction to: Cell Death and Disease https://doi.org/10.1038/ cddis.2017.359, published online 3 August 2017

Following publication of this article it was noted that there were errors in figures 4 and 6 . In figure $4 a$, the $\beta$-actin control was the same as the control used in Figure $6 \mathrm{~d}$, in addition, the ERK1/2 in Figure 4a was flipped horizontally. In Figure $6 \mathrm{a}$, two of the migration images of MHCC-97L cells were chosen by mistake, and were the same as two of the invasion images of the Huh 7 images in Figure $6 a$. The corrected images are shown below. This correction does not change the description, interpretation, or the original conclusions of the manuscript. The authors apologize for any inconvenience caused. 
Fig. 4.

a

SMMC-7721-pWPXL SMMC-7721-PEDF

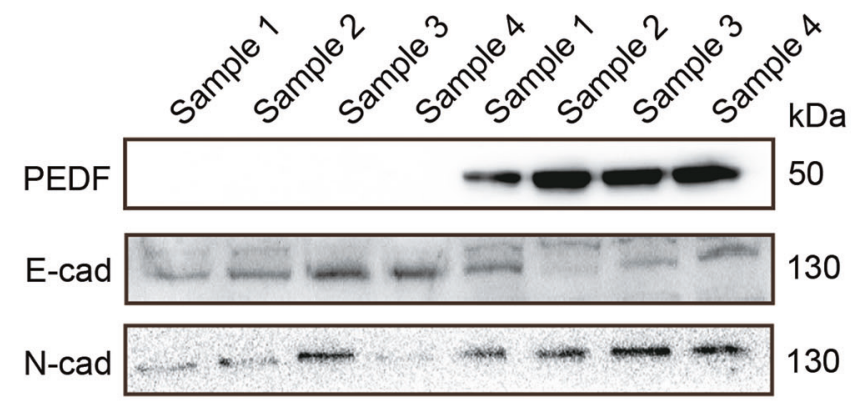

slug $30 \ldots+60$
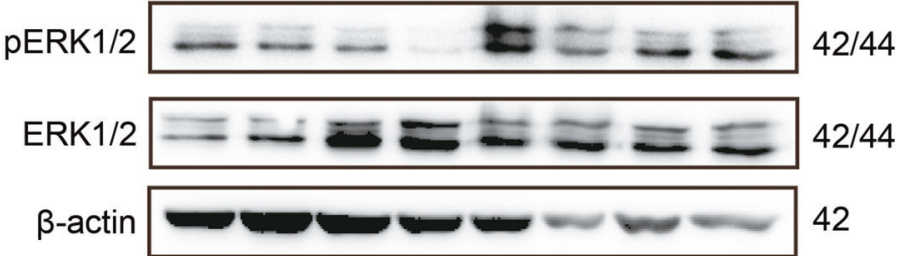

b SMMC-7721-pWPXL

SMMC-7721-PEDF

intrahepatic intrahepatic

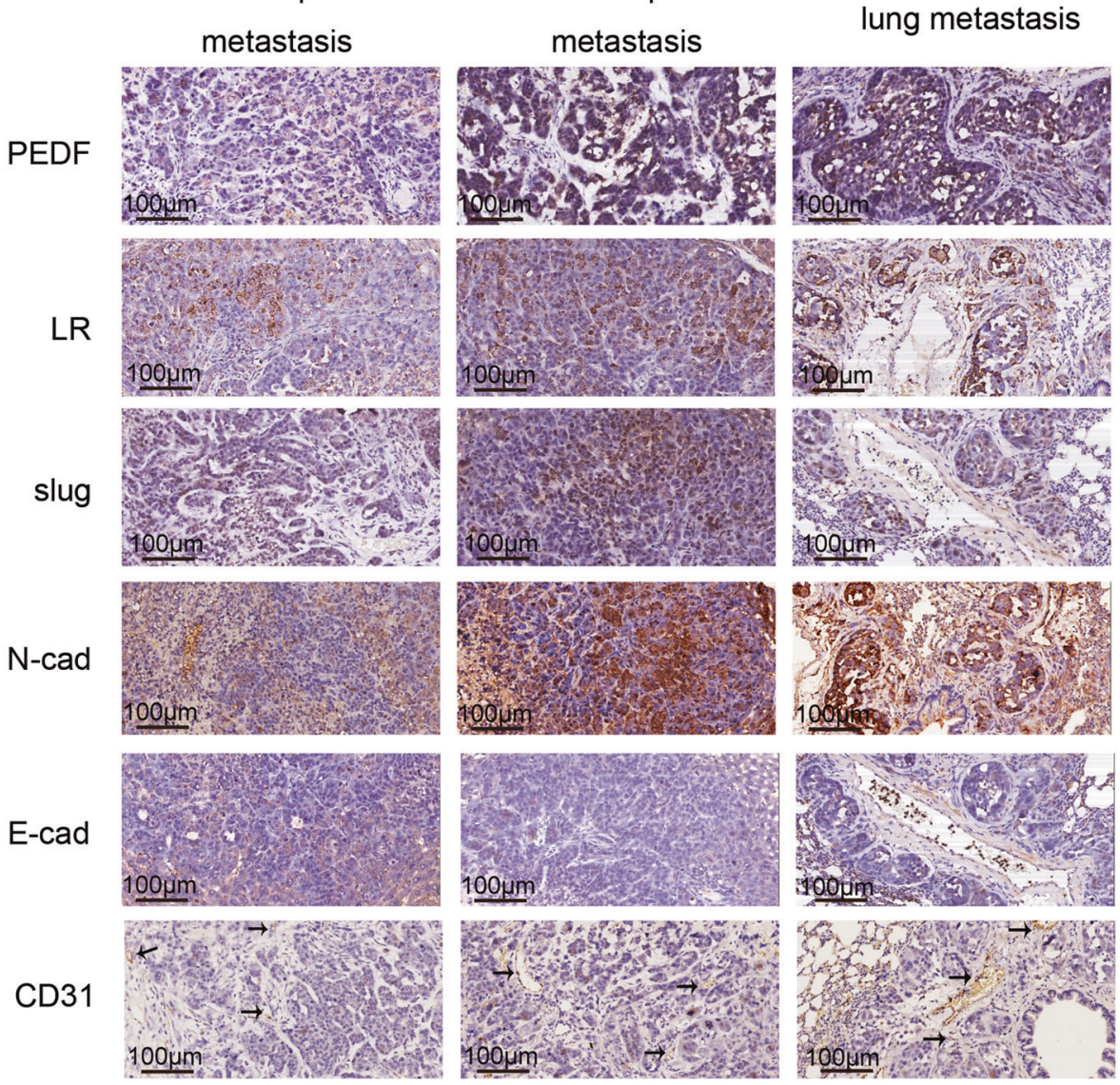


Fig. 6 .

a

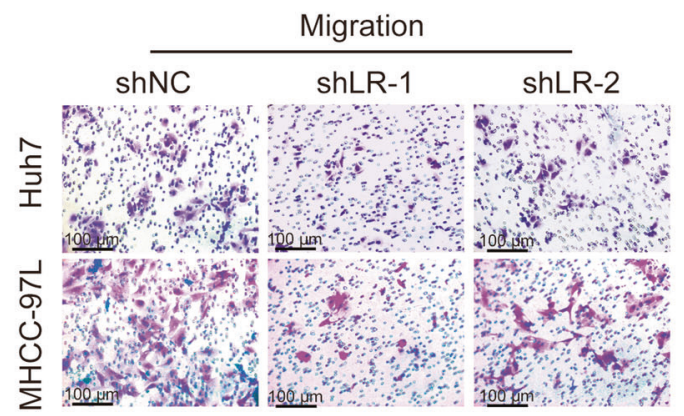

b
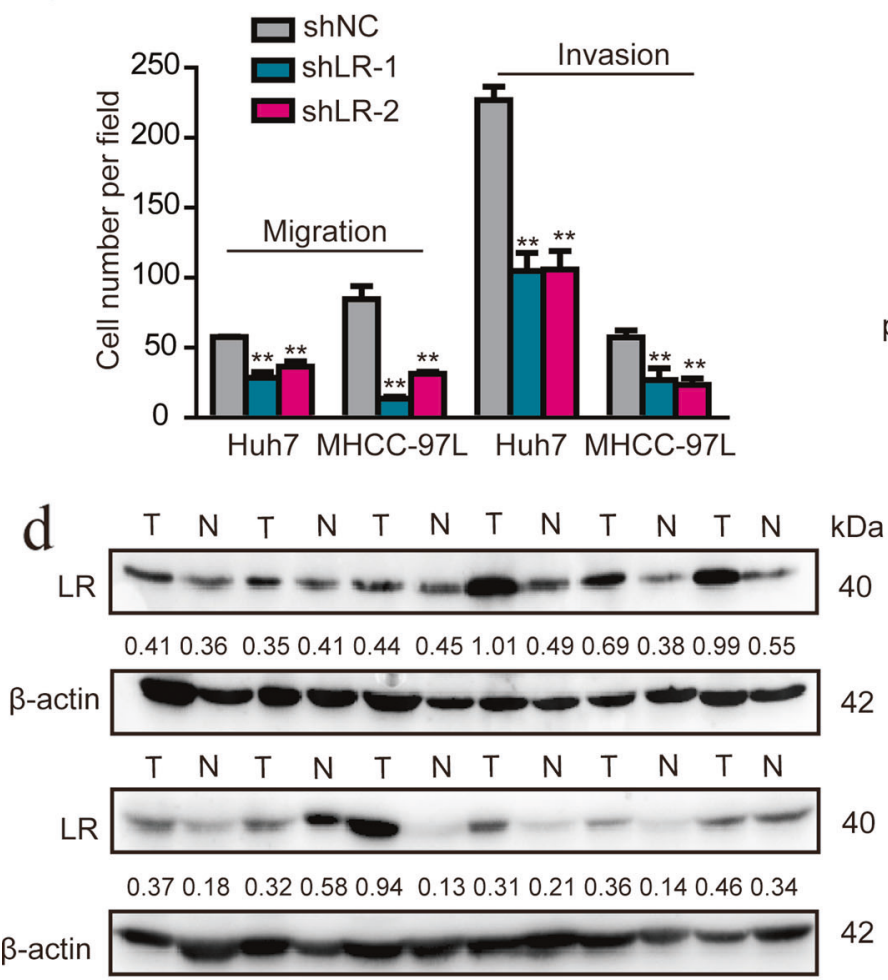

f

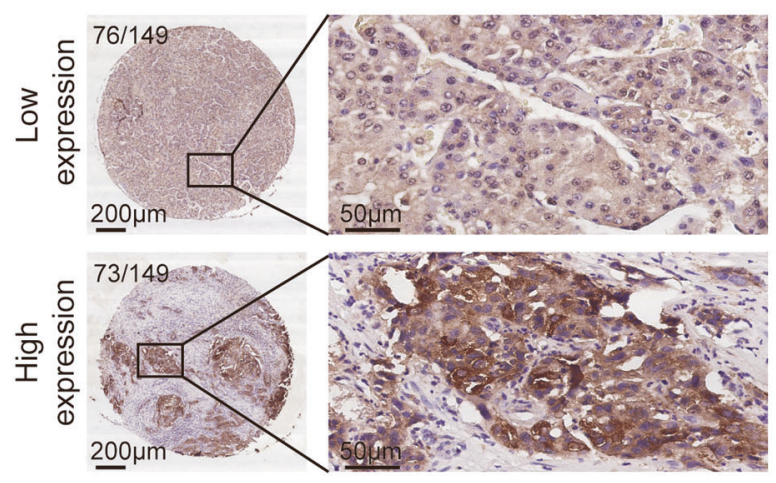

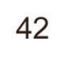

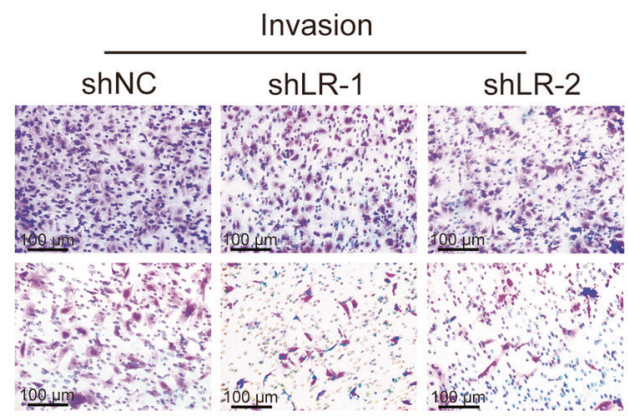

C

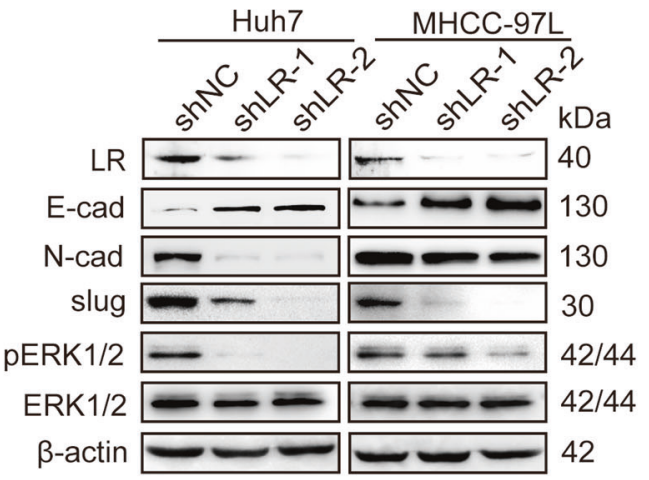

e

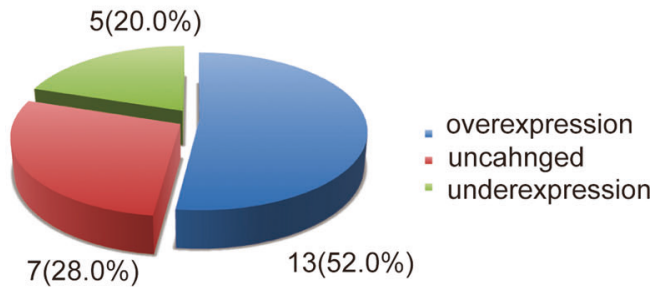

42

g

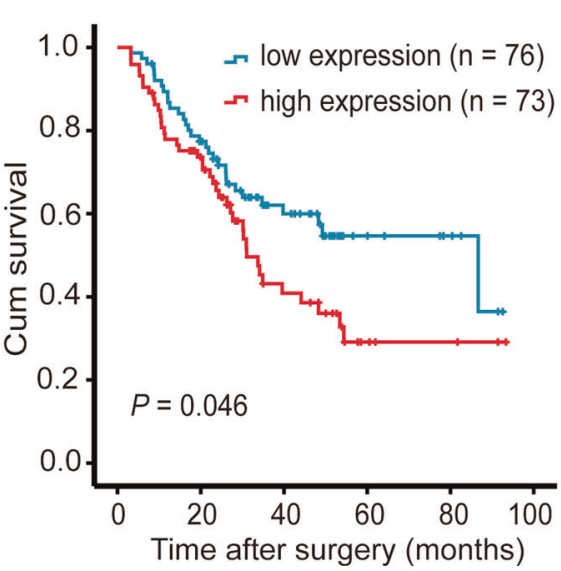


(c) Open Access This article is licensed under a Creative Commons Attribution 4.0 International License, which permits use, sharing, adaptation, distribution and reproduction in any medium or format, as long as you give appropriate credit to the original author(s) and the source, provide a link to the Creative Commons license, and indicate if changes were made. The images or other third party material in this article are included in the article's Creative Commons license, unless indicated otherwise in a credit line to the material. If material is not included in the article's Creative Commons license and your intended use is not permitted by statutory regulation or exceeds the permitted use, you will need to obtain permission directly from the copyright holder. To view a copy of this license, visit http://creativecommons. org/licenses/by/4.0/.

(c) The Author(s) 2021 